\title{
A pirâmide desde a primeira pedra
}

CORDEIRO, H. A.

Sistema Único de Saúde

Rio de Janeiro: Editorial AYURI/ABRASCO, 1991, 184 p.

I Jane Dutra Sayd I

${ }^{1}$ Instituto de Medicina Social Hesio Cordeiro, Universidade do Estado do Rio de Janeiro. Rio de Janeiro-RJ, Brasil (jane.sayd@yahoo.com.br). ORCID: 0000-0002-6111-3071

Recebido em: 20/05/2021

Aprovado em: 03/08/2021

Revisado em: 22/08/2021

DOI: http://dx.doi.org/10.1590/S0103-73312021310330

Conheci Hésio professor em 1969. Fui sua aluna e foi um privilégio; fui sua colega respeitosa; e um dos membros do movimento sanitário a sonhar no boteco - para depois realizar na vida. E em seguida começar a ter uma admiração e um carinho pela sua pessoa, que só aumentou com o passar do tempo. Foi um pouco difícil começar uma resenha de seu livro. Resenha não é resumo, é necessário o comentário, conseguir ver o texto como leitor, nem crítico nem obediente, explanando para o próximo leitor o que o livro diz.

Conheci o livro, creio, logo após seu lança mento. Não me lembro do lançamento, mas ele me levou a seguir por uma espécie de excursão pelo interior do estado, explicando o SUS e distribuindo esse livro. Jamais soube por que é tão pouco conhecido. Aviso desde já que é uma pérola, uma grande aula de política com solidez histórica e, para mim, professora velha, uma excelente leitura obrigatória para alunos novos.

O texto é um relato do processo político-institucional em que se deu a reestruturação do sistema de saúde no Brasil, desde a chamada crise da Previdência, com o surgimento das AIS, até a aprovação e promulgação da Constituição de 1988. 
$\mathrm{Na}$ introdução, Hesio apresenta sua proposta de trabalho: sistematizar as experiências de administração pública no INAMPS no período 1985/1988, quando foi presidente desse instituto e se concretizaram as formulações e início da implantação do SUS. Baseia seu relato na análise dos processos decisórios e de seus fatores determinantes ocorridos ao longo do processo de reorganizaçáo do sistema de saúde no Brasil, escolhendo momentos decisivos para aprofundar questôes. Comenta que o processo é complexo, contraditório, inconcluso e está em franco conflito com interesses já de longa data ancorados no aparelho de Estado; há nesse sentido um certo continuum de personagens ao longo da história. Com diferentes feiçôes, existe sempre a tensão entre ampliar e melhorar a previdência em suas funções precípuas ou entregá-la à gestão e ao lucro privados. A história da constituição do SUS não pode, assim, ser dissociada da própria história das políticas previdenciárias.

Dois aspectos surgem claros no texto, perpassando a narrativa: o primeiro se apresenta já nos agradecimentos, quando diz que o trabalho é fruto de "uma forma solidária de atuação na administração pública.” Agradece aos colegas de jornada e coloca-os na posição de coautores da narrativa, o que é colocá-los também na posição de formuladores e colaboradores ao longo do processo. O segundo aspecto é a valorização da produção de conhecimento como elemento essencial para a formulação de projetos técnicos, de avaliaçooses de políticas, de ação política transformadora.

É muito interessante a ligação fácil que Hesio faz entre a criação de um novo campo de conhecimento, iniciada nos anos 70 , e sua importância para a possibilidade de formular projetos e estratégias viáveis e eficazes em 1985. Ele trabalhou com as categorias e conceitos saídos dessa massa de estudos e não faz separação ou não vê grandes rupturas entre pesquisa e prática política: foi esse corpo de estudos que "sustentou a formulação de alternativas de estratégias para reordenar o sistema de saúde no Brasil”. O esforço teórico realizado pelos grupos de medicina social no Brasil foi fundamental, em sua avaliação, para possibilitar mudanças realmente profundas em estruturas do Estado caducas, como o Ministério da Saúde ou "bichadas" por corrupção e abandono do recurso público, como o INAMPS. Ele utiliza o conceito de anéis burocráticos, de Fernando Henrique Cardoso, para identificá-los no trabalho, assim como o conceito de complexo médico-industrial, de sua própria autoria, para equacionar aspectos do relacionamento com o setor privado, inclusive antecipando a mudança para complexo médico/financeiro efetivamente reconhecida. 
A narrativa segue em sete capítulos. No capítulo II, "As origens do SUS", é contada, de forma concisa, resumida e clara, a chamada "crise da previdência" em 1980/1983, iniciada com o funcionamento do CONASP, um trabalho de reorganização do INAMPS em todos os níveis; ali começou a reforma sanitária, com as primeiras propostas de extensão da rede da previdência a toda a população e as mudanças nas formas de pagamento ao setor privado "as AIS proporcionavam uma base técnica e princípios estratégicos para momentos posteriores da reforma sanitária”. Simultaneamente à inviabilidade da previdência, que apresenta um déficit imenso, é alardeada aos quatro ventos como corrente contrária a mudanças e propondo a privatização pura e simples da previdência no Brasil.

Todo o texto narra, a partir daí, um jogo político em que entram diversos personagens, o setor privado com a indústria de equipamentos, os hospitais e o seguro-saúde; as entidades de classe, sindicatos e outros agentes da sociedade civil, o "movimento sanitário", os anéis burocráticos, elos do setor privado com servidores ou grupos dentro da previdência.

Os capítulos seguintes, "A estratégia da mudança" e "O debate", são uma narrativa que se torna melhor a cada página. É a narrativa de um jogo político, onde se entremeia uma gama de instituiçôes com quem se negociam decisôes técnicas e estratégicas. Um jogo pleno de recuos, avanços e espreitas, que conquista a atenção do leitor. Estão presentes na narrativa os ministérios em questão, mais o Ministério da Educação, os grupos de pesquisa voltados ao tema, partidos políticos e grupos autônomos da sociedade civil. E grupos privados, desde hospitais, passando por empresas de seguro saúde e gigantes do complexo médico-industrial.

O SUDS, capítulo V, apresenta um pedregal de dificuldades para a organização do sistema de saúde de forma regionalizada e descentralizada antes de passar a previdência para o Ministério da Saúde.

Que o SUS possa ter-se organizado a partir do gigantismo e da complexidade ou confusão descritas como quadro institucional do INAMPS em 1985 chega a ser impressionante. A burocracia era um inimigo formidável, infestada de alianças espúrias com interesses privados das mais diversas origens, onde intervençôes e mudanças necessárias e possíveis foram apoiadas pelo ministro. Mesmo assim, qualquer mudança era difícil.

A palavra cautela se faz presente em diversas situaçóes de potencial conflituoso: "Os documentos eram cautelosos ao tratar das relaçôes com os prestadores privados 
de serviços de saúde [...]” (p. 40). “Toda a cautela era necessária no sentido de não gerar resistências entre os sindicatos de trabalhadores urbanos [...] assegurando-lhes a continuidade do atendimento" (p. 44). "O discurso cauteloso se intrometia entre os limites estreitos da transição democrática" (p. 48). "Igualmente cauteloso foi o adiamento da transferência do INAMPS para o min da saúde” (p. 48).

Este é, talvez, o momento em que a capacidade de análise política e estratégica do grupo se revela astuta ou sábia, como se queira. A proposta existe desde o CONASP e está explícita em documento inédito enviado a Tancredo Neves. Havia unanimidade a respeito da "entrega" da Previdência a um sistema universal situado no min da saúde. Houve, no entanto, a "descoberta da complexidade burocrática do INAMPS, altamente centralizada em suas decisóes, com instrumentos gerenciais de controle precários e desarticulados". A burocracia técnica do INAMPS decidiu desenvolver mais as AIS como etapa de descentralização e de desmontagem da pesada máquina administrativa antes de fazer a transferência.

A mudança que se pretendeu foi uma regionalização e descentralização das atividades, de modo que cada estado começou a operar o seu SUDS. E os que queriam uma transferência "por cima" imediata, mantendo a estrutura anterior, entraram em choque com a proposta. A administração por convênios parecia facilitar a volta de clientelismos na relação com os estados. Críticas à esquerda e à direita bombardeavam a estrutura provisória recém-inaugurada.

Um debate intenso recomeçou a partir da criação da Comissão Nacional de Reforma Sanitária, que pretendia assentar com mais solidez os princípios da VIII Conferência Nacional de Saúde. Não se conseguiu o resultado pretendido: "as soluçôes de compromisso para atingir algum grau de consenso" entre representantes sindicais, lideranças comunitárias, representantes dos empresários da saúde e os segmentos técnico burocráticos dos ministérios. Chega a parecer piada, mas algumas coisas se conseguiam.

Além da política cautelosa, outro ponto que chama a atenção é a presença do movimento sanitário, assinalada por Hesio com muita frequência. Um ser que não tem forma nem tamanho definido, mas é consultado, vai a reunióes e é, indiscutivelmente, uma força política. Hesio faz parte dele como um dos fundadores e ouve o movimento. Mas não se sabe quem faz parte dele exatamente. Nas lutas dentro do CONASP, uma lista se apresenta grande: médicos do movimento sindical REME; outros sindicatos de profissionais de saúde; institutos e centros de pesquisa 
em saúde pública e medicina social; CEBES; ABRASCO; setores do movimento sindical mobilizados pela saúde dos trabalhadores; federaçóes e confederaçóes de trabalhadores na agricultura. Esse movimento da reforma sanitária se estende e busca “os espaços para absorção e aceitação de propostas do movimento sanitário" (p. 32).

Em 1984, a Câmara dos Deputados promoveu um simpósio marcado para se buscar um consenso "entre o movimento sanitário e entidades privadas" (p. 39), "uma reunião para avaliar as AIS organizada pelo CEBES e ABRASCO reforçou a posição do movimento sanitário [...]" (p. 39) e "assim foi sendo construído um consenso pelo menos no movimento sanitário," (p. 40). Para "a presidência do INAMPS, o movimento sanitário fixava-se em dois nomes [...]" (p. 41). "O movimento sanitário teve que aprender [...] viram com desconfiança o movimento sanitário [...]” (p. 53).

Hésio não se sentia só; considerava sua equipe como coautora do livro e, do mesmo modo, creio, considerava necessário ouvir e debater no interior da entidade, metafísica porém real, o movimento sanitário. E assim se chegou à VIII Conferência Nacional de Saúde e seu relatório, e à nova Constituição onde a saúde se apresenta como direito e dever do Estado.

Os capítulos V, VI e VII narram o pedregal para universalizar, fazer adaptaçóes na burocracia, conseguir executar a descentralização "o processo de descentralização implicaria uma necessária redução da máquina administrativa com a eliminação de cargos em comissão” (p. 121), “ não interessava a diversos segmentos do setor privado a descentralização [...] (p. 121).

E houve também as mais diversas dificuldades na implantação dos SUDS em algumas regiōes ou locais. Sobre esse tema, Hesio se apoiou nos "Comentários sobre a institucionalização do SUS”, realizado por Francisco Costa Neto, procurador do INAMPS, mostrando a adequação e legalidade das normas e condutas propostas. Esse período terminou com a saída de Renato Archer do MPAS e do governo. Sarney nomeou como presidente do INAMPS um médico amigo da família, Dr. José Ribamar Pinto Serrão, para "responder pelo expediente".

E aqui termina a história da construção inicial do SUS narrada por Hesio, este como agente ativo e protagonista no processo. Segue-se a narrativa melancólica das distorçôes iniciadas no projeto, através da manipulação do aporte de recursos, com retorno ao favorecimento do setor privado e apaniguados políticos, e se encerra com a discussão da Lei Orgânica da Saúde no Congresso. 
Há uma certa continuidade nos artigos publicados no período 1988-90 nos jornais O Dia, Jornal do Brasil, O Globo, Folha de São Paulo e Tribuna da Imprensa, publicados como anexos ao livro. Vale a pena acompanhar a evoluçáo do processo pelas crônicas ou artigos.

Esse livro narra uma história real, com sobriedade e rigor, de uma iniciativa política que "vingou”. Merece divulgação. E repito: vale a pena ler.

\section{Referência}

CORDEIRO, H. A. Sistema Único de Saúde. Rio de Janeiro: Editorial AYURI/ABRASCO, 1991, $184 \mathrm{p}$. 